\title{
Traction BEHAVIOUR SimUlation OF SPOT WELDED
}

\author{
CATANA, D.
}

Abstract: For a lot of production areas but particularly for automotive industry spot welding is one of the mostly used welding procedures. Most of these welding spots are arranged in line but this displacement is not always the best choice regarding traction behaviour. There are situations when no physical space is available to line up the welding spots in which case another arrangement should be found. In this paper are presented simulation and test results for spot welded joints under traction stress but for different spot arrangement. This study is based on tests on spot welded joints in which the spots were disposed in different patterns such as: square, parallelogram and rhombus. Based on tests, square arrangement turned out to be the most convenient solution. A better traction resistance for welded joint means less welded spots and means energy saving.

Key words: FEM, behaviour, welding, spots
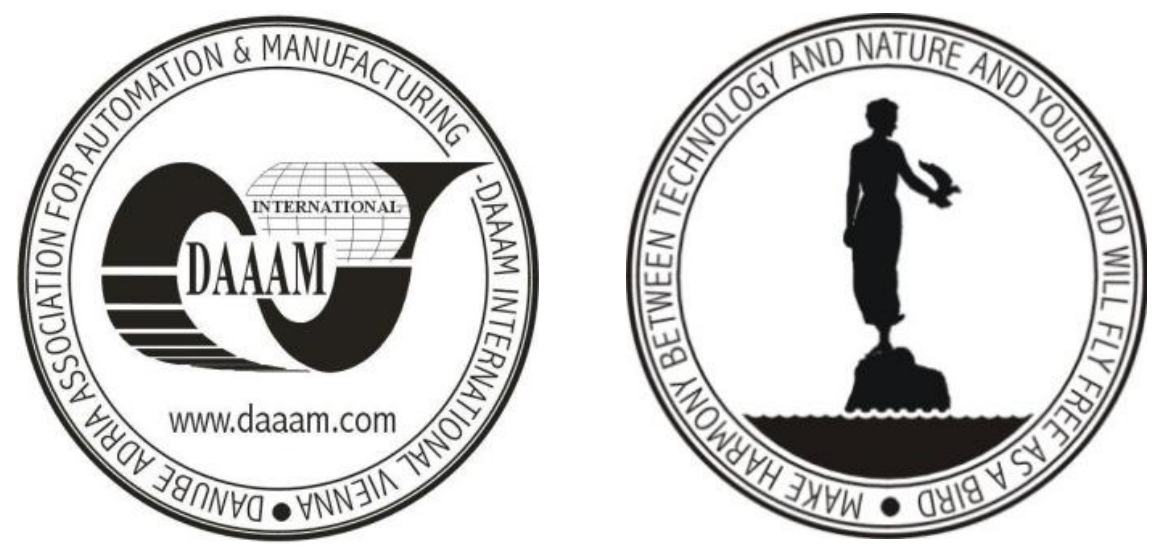

Authors' data: Univ. Assoc. Prof. Dipl.-Ing. Dr. techn. Catana, D[orin], University Transilvania of Brasov, B-dul Eroilor 29, 500036, Brasov, Romania, catana.dorin@unitbv.ro

This Publication has to be referred as: Catana, D[orin] (2010). Traction Behaviour Simulation of Spot Welded, Chapter 50 in DAAAM International Scientific Book 2010, pp. 575-582, B. Katalinic (Ed.), Published by DAAAM International, ISBN 978-3-901509-74-2, ISSN 1726-9687, Vienna, Austria

DOI: $10.2507 /$ daaam.scibook.2010.50 


\section{Introduction}

Finite element method is a powerful and efficient instrument in design and scientific research with multiple and various applications, but also a main component of computer research and design.

At the beginning was used in mechanical calculus of main frames, especially in aircraft industry. Lately, finite element method extended its area of utilization for the whole engineering activity, being successfully used to solve the issues regarding the composition of materials. The expansion of using the finite element method is due, on one hand, to its general character of it fundamental concept formulation, fact that allowed its utilization in numerous domain of science and technology, and on the other hand, its capacity to improve studied physics phenomena comparable with other numeric computation methods, fact that allowed to be preferred by many specialists.

A high fidelity reflection of materials and structures behaviour is a major exigency required by designers and used calculus methods being the primary condition for a rigorous dimensioning and accomplishing for important material savings, energy and labour. From this point of view, finite element method (FEM) is superior to all the other calculus methods.

The possibility of a precise investigation of materials behaviour is also encouraged by study and spreading of replacing materials which is another economic advantage.

The development of this method is reflected by increasing number of publications and worldwide scientific sessions. Highly significant is the increasing number of FEM calculus software, the fact that software companies are preoccupied with supplying of these products together with calculus equipments as base soft, and as well, the development of dedicated computers for finite element calculus and its hardware components, with software included, which allow general use computers to be able to perform finite element calculus by a simple installation of the software.

\section{Theoretical considerations}

FEM is an approximated solving procedure, by the mean of an electrical computer, of a great variety of engineering problems. Among these problems, belong those problems that deal with metallic materials welding.

In order to shape a geometric domain can be used dots, straight or curved lines, plane or curve surfaces. The geometrical modelling algorithm is generally done on sub-domains, with a convenient choice for the runs from one sub-domain to another. In order to choose the nodes and sub-domains a method called digitization is required. By using this method real continuous domain is replaced with an ideal digitised domain composed of smaller sub-domains.

In figure 1 a two dimensional domain " $D$ " is showed which has been digitised in triangular finite elements (figure 1.a), with edges straight or curved lines (figure 1.b). For the finite elements with straight lines, digitised error can be reduced by increasing the number of nodes and therefore the number of finite elements. For finite 
elements with curve edges, digitised error can be reduced due to curve boundaries of finite elements (Catana, 2004).

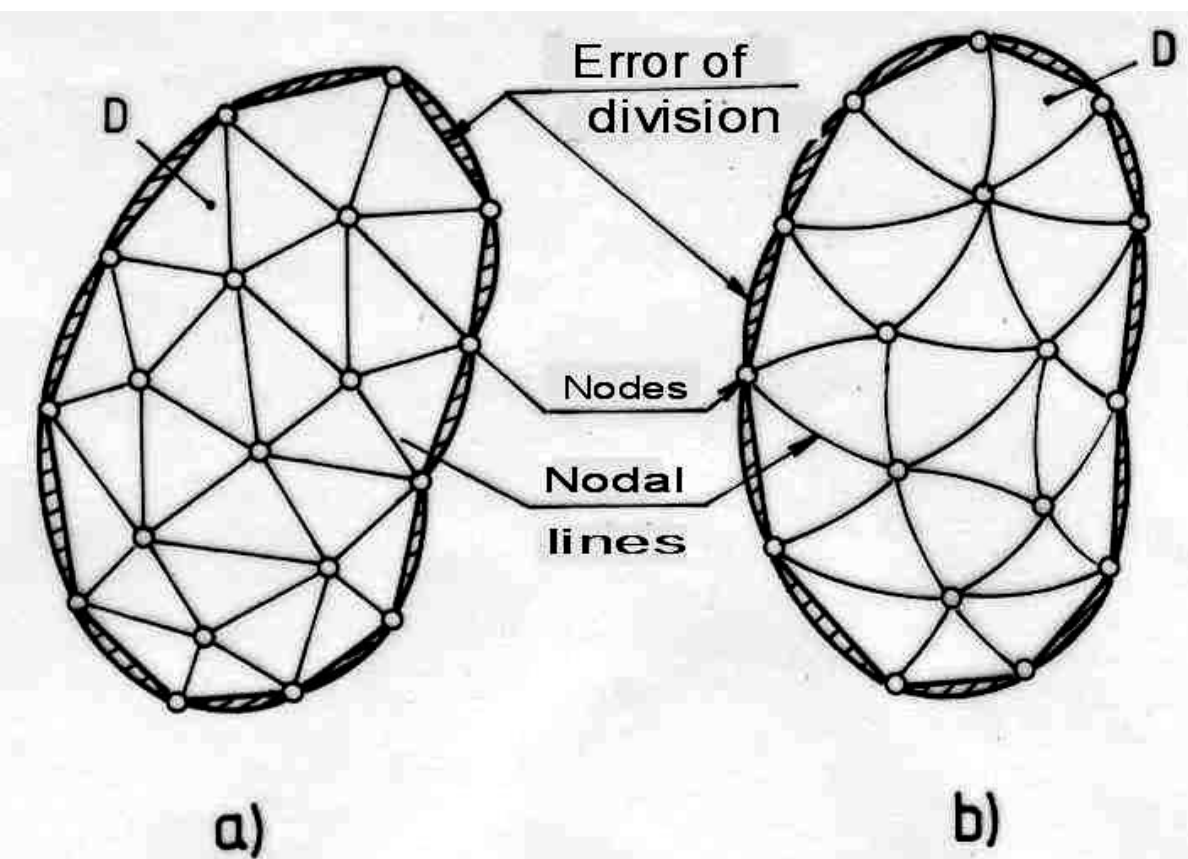

Fig. 1. Digitising the domain for finite elements

For spot welding case these dimensions and therefore the allowable stress depends on welding process parameters. Welding will be performed in a soft or hard regime.

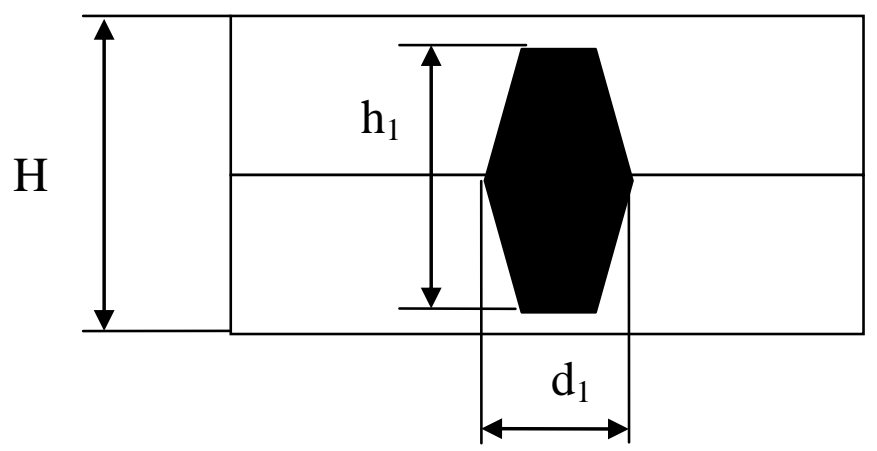

Fig. 2. Soft regime welding spot dimension

In case of soft regime (see figure 2), a larger metal volume is heated, which exceeds welded spot area and the electrodes in contact with the metal in plastic state will leave deep marks in the components to be welded. In case of hard regime (see figure 3), only the spot welded area is brought to a high temperature, welding being finished before the surface of elements to be welded in contact with electrodes to reach a high temperature (Iovanas, 2004).

By comparison the spot dimension obtained with these two welding regimes we have:

- $d_{2}>d_{1}$ - which means that shear resistance of welded spot with hard regime is higher than that one obtained with soft regime welding (Novac, 1994); 
$-\mathrm{h}_{2}<\mathrm{h}_{1}$ - which means that at soft regime a bigger volume of melted metal is obtained and therefore more dendrite structure, which is more fragile and less resistant; for hard regime $h_{1} \cong 0,3 \mathrm{H}$, and for soft regime $h_{2} \cong 0,9 \mathrm{H}$.

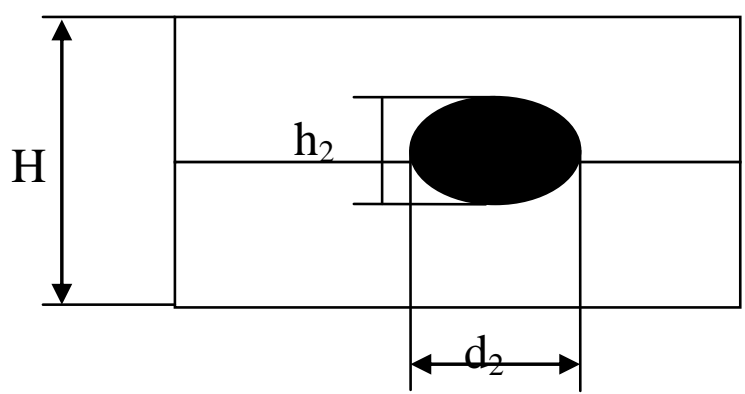

Fig. 3. Hard regime welding spot dimension

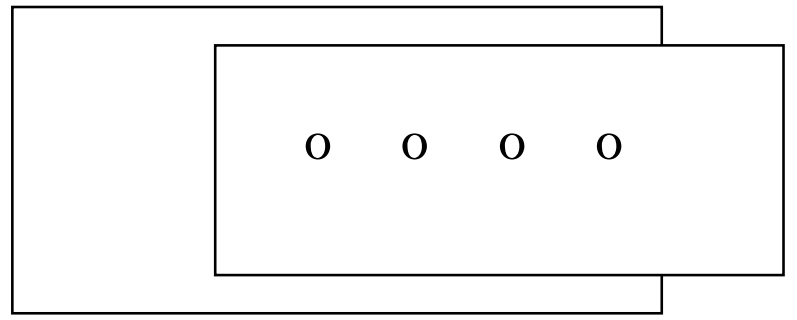

a)

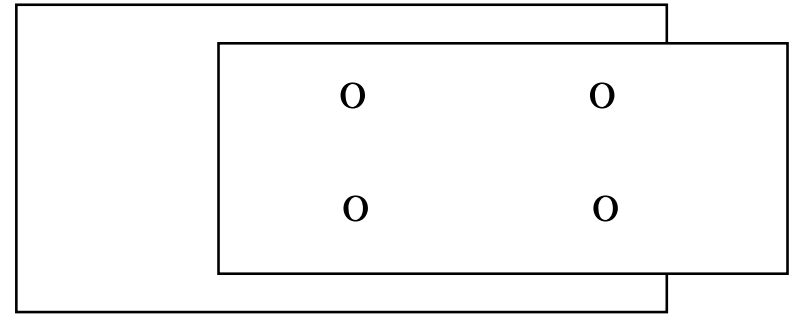

b)

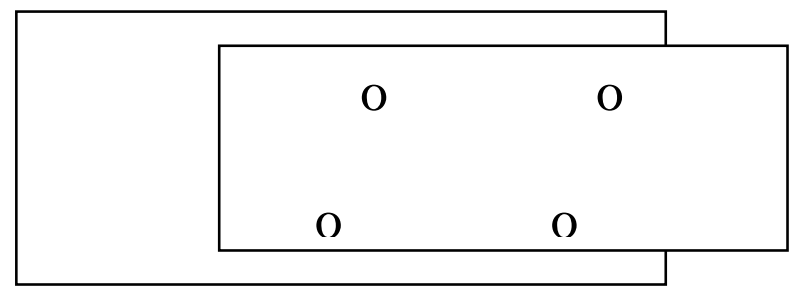

c)

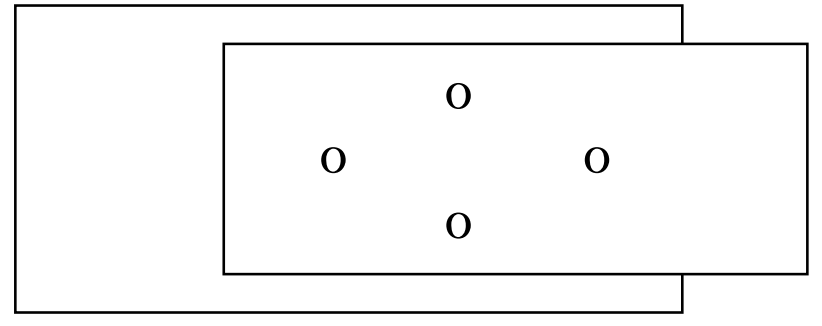

d)

Fig. 4. Spot welding arrangement: a) in line, b) in square, c) in parallelogram, d) in rhombus 
Therefore the traction behaviour of a spot welded joint will be tested (see figure 4) (four different spots will be arranged). Due to forces that stress the joining, within the material stress will be present and when these will exceed material breaking strain will determine the damage of welded joint.

The welding spots were arranged as follow:

- in line;

- in square;

- in parallelogram;

- in rhombus.

The study of welded spots arrangement influence has been done on $\mathrm{A}_{3}$ (STAS 9485-80) metal sheet samples with next chemical composition:

$\mathrm{C}-\max 0.08 \%$;

$\mathrm{Mn}-0.2 \ldots 0.4 \%$;

$\mathrm{Si}-0.03 \%$.

Mechanical characteristics of used material are:

- yield limit $\mathrm{R}_{\mathrm{p} 0,2}$ - Max $240 \mathrm{MPa}$;

- breaking strength $-270 \ldots 370 \mathrm{MPa}$;

- breaking elongation $-\mathrm{A}_{5} \min 34 \%$.

Used parameters of the welding regime as well as the results are presented in table 1 (Catana \& Machedon-Pisu, 2003).

\begin{tabular}{|c|c|c|c|}
\hline $\begin{array}{c}\text { Spot } \\
\text { arrangement }\end{array}$ & Regime I & Regime II & Regime III \\
\hline $\begin{array}{llll}\mathrm{O} & \mathrm{O} & \mathrm{O} & \mathrm{O}\end{array}$ & 256 & 433 & 571 \\
\hline $\begin{array}{ll}0 & 0 \\
o & 0\end{array}$ & 258 & 497 & 596 \\
\hline $\mathrm{o}^{\mathrm{O}} \mathrm{o}^{\mathrm{O}}$ & 260 & 532 & 583 \\
\hline $\begin{array}{lll} & \mathrm{O} & \\
\mathrm{o} & & \mathrm{o} \\
& \mathrm{o} & \end{array}$ & 229 & 458 & 546 \\
\hline
\end{tabular}

Tab. 1. Breaking force of spot welded joints [daN]

Regime I: I=3 kA, t=3 [per];

Regime II: I= $5 \mathrm{kA}, \mathrm{t}=5$ [per];

Regime III: $\mathrm{I}=6 \mathrm{kA} \mathrm{t}=5$ [per].

The thickness of metal sheets was $0.4 \mathrm{~mm}$, spot welding method being used to join two components of equal thickness and with the electrodes having the same constructive parameters. After having welding joint done, these have been tested at tension test accordingly to the standard (Catana, 2005). For all regimes the traction speed was: $v=6.5 \mathrm{~mm} / \mathrm{min}$ and the dimensions of the electrodes were $(10 \mathrm{~mm}$ diameter for body and $6 \mathrm{~mm}$ for peak). Welded spot arrangement will determine the development in welded joint of different stresses for different areas of the welded 
joint. The impact of welded spot arrangement regarding the strength within welded joint is presented using simulation method in figure 5 .

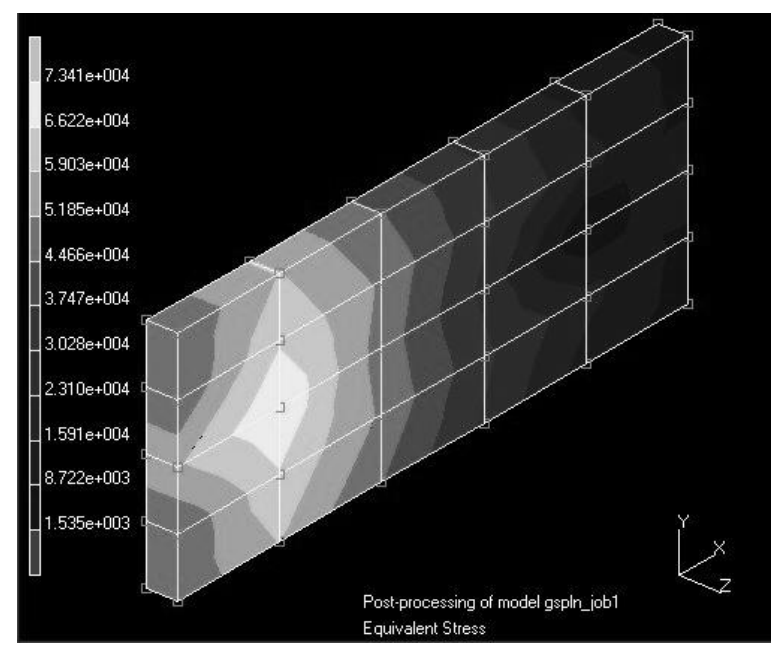

a)

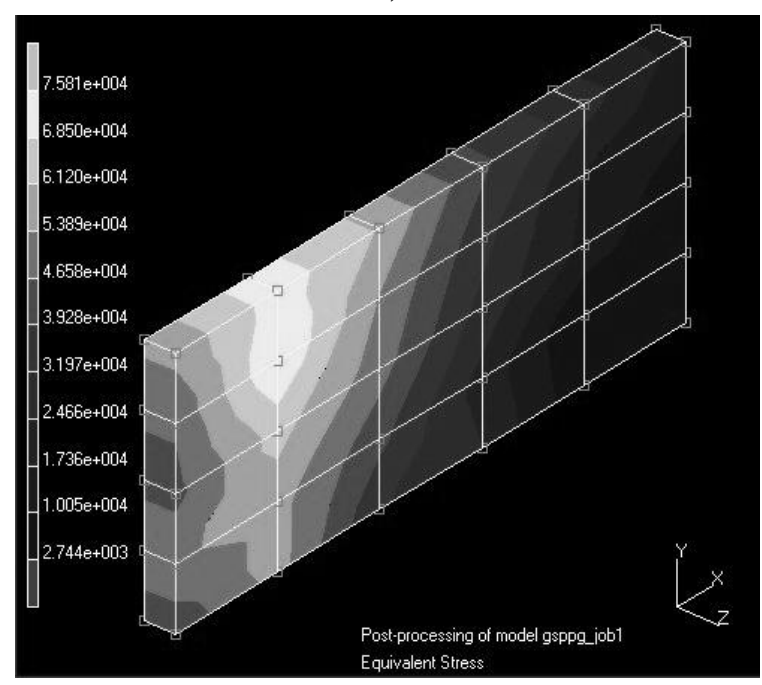

c)

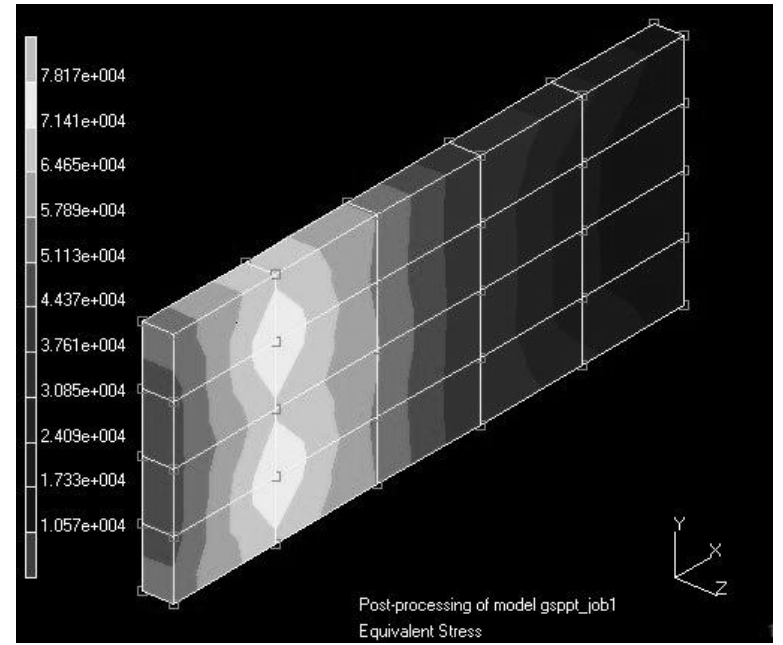

b)

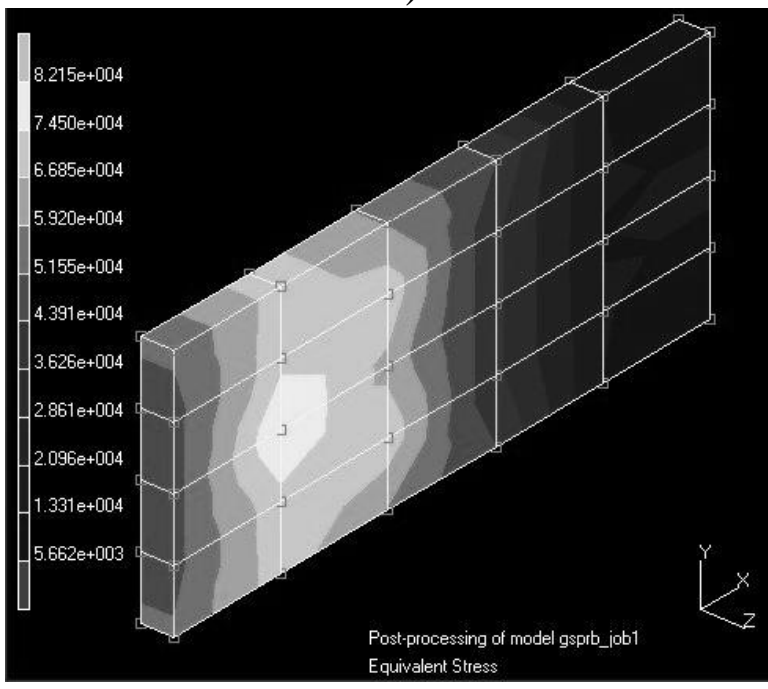

d)

Fig. 5. Equivalent stress development in a spot welded joint: a) in line points b) square points c) parallelogram points d) rhombus points

During the tests was noticed that regarding the stresses developed within the joint rhombus shape arrangement is not the most convenient one. A new stage of the researches for this type of joint was the obtaining of different welded spots at different parameters regarding welding conditions (see figure 6).
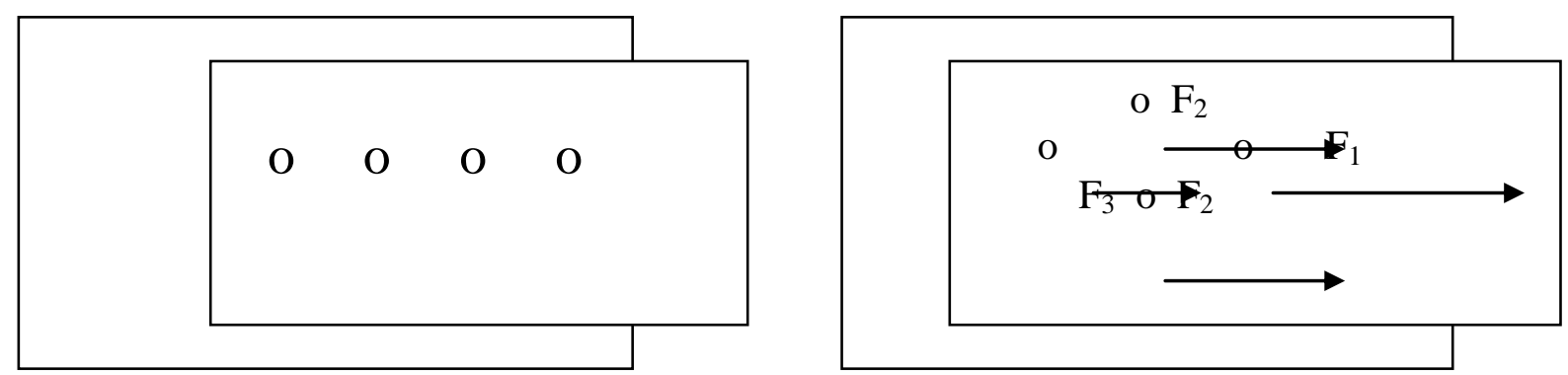

Fig. 6. Welding spot arrangement with shearing forces 
By simulation it is possible to obtain information regarding stress development within the spot under traction. A case of stress simulation is presented in figure 7 .

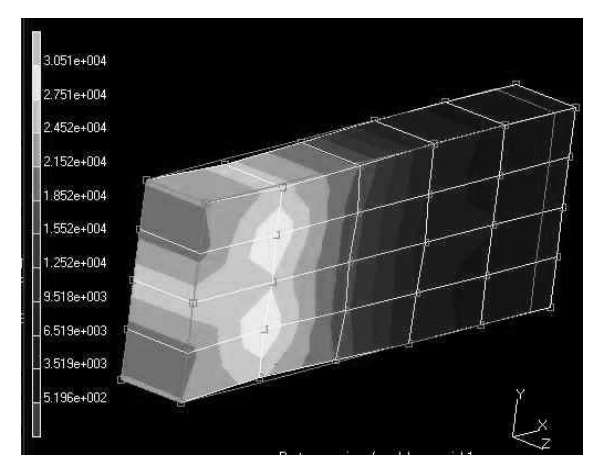

a)

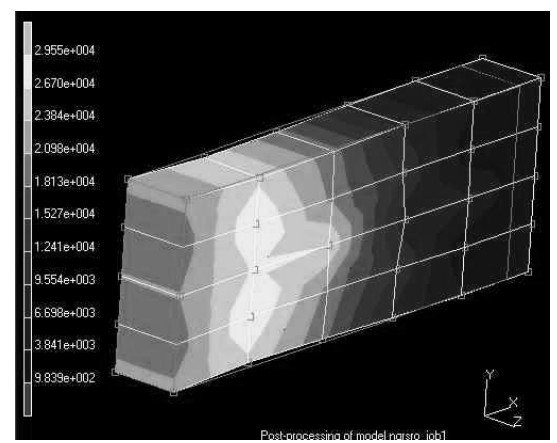

b)

Fig. 7. Equivalent stress development in a spot welded joint: a) classic; b) combined

This study is completed with the experimentally results. The tests have been done on samples made of metal sheet $\mathrm{A}_{3}$ (STAS 9485-80), with next chemical composition $\mathrm{C}-\max 0.08 \%, \mathrm{Mn}-0.2 \ldots 0.4 \%, \mathrm{Si}-0.03 \%$.

\begin{tabular}{|c|c|c|c|}
\hline $\begin{array}{c}\text { Intensity } \\
\text { percentage }\end{array}$ & I [kA] & $\begin{array}{c}\text { Welding } \\
\text { time [s] }\end{array}$ & $\begin{array}{c}\text { Spot shearing force } \\
{[\text { daN/point] }}\end{array}$ \\
\hline I (37) & $\mathbf{5 . 4}$ & $\mathbf{0 . 8}$ & $\mathbf{5 5 0}$ \\
\hline II (38) & 5.5 & 0.8 & 1000 \\
\hline III (39) & 5.7 & 0.8 & 1466 \\
\hline IV (40) & $\mathbf{5 . 8}$ & $\mathbf{0 . 8}$ & $\mathbf{1 9 2 5}$ \\
\hline V (44) & 6.38 & 0.8 & 3495 \\
\hline VI (45) & $\mathbf{6 . 5}$ & $\mathbf{0 . 8}$ & $\mathbf{3 8 3 0}$ \\
\hline VII (47) & 6.9 & 0.8 & 4000 \\
\hline VIII (50) & $\mathbf{7 . 2 5}$ & $\mathbf{0 . 8}$ & $\mathbf{4 1 8 0}$ \\
\hline
\end{tabular}

Tab. 2. Spot shearing force

After testing, one spot welding has been achieved; the joint was tested at shearing traction accordingly to the standard and was established supported force. The results are presented in table 2. The thickness of metal sheets was $1.2 \mathrm{~mm}$, spot welding method being used to join two components of equal thickness and with the electrodes having the same constructive parameters.

The results of I, IV, VI and VIII rows were obtained using experimentally channels while those of interpolated rows using linear and parabolic method. At the base of the results a rhombus shape spot welding was achieved and welding condition parameters have been established where shearing force at yielding point has a definite value considering joint loading scheme (first line has the biggest load, the second line a smaller one and the last line the smallest load value). Welded spots have been achieved as follow:

- classic $\mathrm{F}_{1}=\mathrm{F}_{2}=\mathrm{F}_{3}=\mathrm{F}_{4}=1925 \mathrm{daN}$ (total $\mathrm{F}=7700 \mathrm{daN}$ );

- combined $\mathrm{F}_{1}=3495 \mathrm{daN}, \mathrm{F}_{2}=\mathrm{F}_{3}=1466 \mathrm{daN}, \mathrm{F}_{4}=550 \mathrm{daN}($ total $\mathrm{F}=6977$ daN); 
- theoretically $\mathrm{F} 1=4000$ daN, $\mathrm{F}_{2}=\mathrm{F}_{3}=1000$ daN, $\mathrm{F}_{4}=1000$ daN (total $\mathrm{F}=$ $7000 \mathrm{daN})$. For all regimes the traction speed was: $\mathrm{v}=7.5 \mathrm{~mm} / \mathrm{min}$ and the dimensions of the electrodes were (10 mm diameter for body and $6 \mathrm{~mm}$ for peak).

Due to forces within the joint, stresses will appear, spot resistance value will be over passed and this fact will lead to the destruction of it. Welded spot arrangement will determine the development in welded joint of different stresses for different areas of the welded joint (see figure 7).

\section{Conclusions}

Spot welding is used to produce body cars of all types in car industry, electro technical and home appliances. This method fits most welding operation automation. From the analysis of results obtained through simulation a conclusion derives that the most convenient arrangement of welded spots is the square one where developed stresses are symmetrical and have lower values. Based on tests, line and rhomb arrangements are not to be preferred taking into consideration the value of tensions and the required space. Test results showed that parallelogram arrangement is unwanted and should be avoided when spot welding procedure is used. Research plan will continue with studying the influence over traction resistance for spot welded joints as well for the distance on longitudinal and across direction for different spot welding arrangements.

The simulation can be improved through a realistic modelling closer as possible to the way in which forces strain the joint, more precisely by establishing the volume of welded spot and its position within the joint. Using simulation study of achieved welded spots the results will lead to the same conclusions from experimental channel. Based on the results a conclusion can be drawn that the most convenient way to realize welded joints is combined and eventually theoretical method.

\section{References}

Catana, D. \& Machedon-Pisu, T. (2003). The simulation of behaviour at traction of spots welded joints. Sudura, Vol. XIII, No. 2, 2003, 23-27, ISSN 1453-0384

Catana, D. (2004). The study through simulation of the stress developed in the spots welded joints solicit at traction, Proceedings of International Scientific Conference „Modern Technologies, Quality, Restructuring” TMCR 2004, Musca, G., pp. 461-464, ISSN 1011-2855, Jassy, 05-2004, Bulletin of Polytechnic Institute of Jassy, Jassy

Catana, D. (2005). Theoretic contributions for the plastic deformation simulation process, Proceedings of International Scientific Conference „Modern Technologies, Quality, Restructuring” TMCR 2005, pp. 333-337, ISBN 99759875-4-0, Technical University of Moldova, 05-2005, University of Moldova, Chisinau

Iovanas, R., (2004). Spots pressure welding, Lux Libris, ISBN 973-9240-71-8, Brasov

Novac, G., (1994). Welded joints calculus, Lux Libris, ISBN 973-96308-7-1, Brasov 